\title{
THE NONLINEAR ASYMMETRIC RELATIONSHIP AMONG IMPLIED VOLATILITY INDICES OF INDIAN STOCK MARKET, GOLD, AND OIL: EVIDENCES FROM NARDL MODEL
}

\author{
Dr. Jyothi Chittineni \\ Assistant Professor \\ Finance and Accounting \\ IBS - Hyderabad, The ICFAI Foundation for Higher Education \\ (Declared as Deemed-to-be University U/s 3 of the UGC Act 1956) \\ Dontanapally Campus, Shanker Pally Road, Hyderabad, India \\ E-mail: Jyothi.chittineni@ibsindia.org \\ Dhttps://orcid.org/0000-0002-3838-6995
}

Received: October 13, $2021 \quad$ Accepted: November 15, $2021 \quad$ Online Published: January 14, 2022

DOI: $10.46281 /$ ijfb.v9i1.1540

URL: https://doi.org/10.46281/ijfb.v9i1.1540

\begin{abstract}
The paper aims to examine the nonlinear asymmetric relationship among the implied volatility indices of the Indian stock market, gold, and oil for the period from $2^{\text {nd }}$ March 2009 to $29^{\text {th }}$ October 2021. Nonlinear Autoregressive Distributed Lag (NARDL) model results provide evidence of asymmetric nonlinear relationship among the selected variables in the short-run and the long-run. The positive and negative shocks to gold and oil implied volatility indices have a positive and significant influence on the implied volatility of the Indian stock market. The expected volatility of gold has a short-term symmetric impact on expected stock market volatility in the short run. Whereas, the implied volatility of oil has a long-run asymmetric impact on the implied volatility of the stock market. Increasing volatility in oil prices can be viewed as a signal for the starting point for the volatility of the Indian stock markets. In the long run, positive shocks to gold volatility have more impact on the expected volatility of the Indian stock market than the negative. This indicates that investors are shifting their investments from gold to stocks for higher returns when the gold prices are fluctuating.
\end{abstract}

Keywords: Nonlinear Autoregressive Distributed Lag, Implied Volatility Index, Asymmetric Relationship, Oil, Gold.

JEL Classification Codes: G10, G11, G13, G15.

\section{INTRODUCTION}

Many economies liberalized their financial policies and trade policies to attract capital in-flows and to increase international trade volumes. These liberalized trade policies and financial policies integrated the economies as global villages. The positive side of these liberalized economies is that the developing economies could attract the capital inflow from developed economies. The other side of this integration is that the financial shocks and macroeconomic variables volatility is also transmitting from developed economies to developing economies. 
India being an emerging economy, it is largely depending on the developed economies for investments and trade. Indian economy is dependent on oil and gold markets because it is the biggest importer of oil and the consumer for the gold. India's annual demand for gold is around 895 tonnes, which is $26 \%$ of the worldwide demand for physical gold. Gold has a very important role in Indian culture and rituals, during weddings and festivals buying gold is considered auspicious. Buying gold is a regular household expenditure, it is considered a symbol of status, wealth, sentiment, safety. India is the largest importer and the consumer of crude oil in the world. Lower crude oil prices narrow the fiscal deficit in India. An increase in crude oil has multiple impacts on the Indian economy.

The Indian economy is more exposed to the price changes of these macroeconomic variables like oil and gold. The stock market prices and the inflation in the country are largely affected by the price changes of these resources. With this background, this paper aims to examine the impact of the future expected volatility of gold and oil on the future expected volatility of The Indian stock market. Unlike other papers, present paper uses expected future volatility as a central theme to understand the causality among these selected variables.

There are several studies conducted to understand the bi-variate, bi-directional and dynamic relationship among stock prices, oil prices and gold prices. Most of these studies conducted on developed economies examined the linear relationship and presented mixed results about the oil, gold and stock prices interaction (Zhang \& Wei, 2010), Most of the earlier studied used VAR and GARCH, DCC GARCH models. Interestingly, there is very little evidence of the causal relationship among the gold volatility index, oil volatility index and the Indian Implied volatility Indices. Therefore, the present study examines the non-linear causal interaction among implied volatility indices of gold, oil and Indian stock markets. Unlike earlier studies present study uses implied volatility indices to understand the non-linear causal interplay among selected variables.

The paper results contribute to the literature in many ways. Firstly, this is one of the very few studies examined on implied volatility indices of stock markets, gold and oil and their interplay. Secondly, this paper uses a larger sample from $2^{\text {nd }}$ March 2009 to $29^{\text {th }}$ October 2021. Thirdly, the present study uses a non-linear autoregressive distributed lag model (NARDL) to understand the short-term and long-term responses to the shocks of one variable towards the other variables.

The remaining part of the paper covers on review of literature, sample period and collection, model specification, empirical results discussions, implications of the study and the conclusions.

\section{REVIEW OF LITERATURE}

Understanding the interplay between the stock market and the alternative assets is very important for the policymakers to design the strategies for sustainable economic growth. Hence, the literature on these variables got attention from academicians, researchers, investors and policy makers. Prior literature indicate that the fluctuations in the oil price has an impact on the economy because the oil price has direct impact on the cost of production and the profit margin (Hammoudeh \& Choi, 2007). Fluctuation in the international oil prices leads to rupee value depreciating and hence the inflation in the country increase (Raj et al., 2008), when inflation increases investors are relying on the safe heaven gold to hedge their portfolio again inflation. The linkage between gold, oil and their movements influences the stock prices (Reboredo, 2013). Sari et al. (2010) found a weak asymmetric relationship between gold and oil prices. Soytas et al. (2009) studied the influence of gold and silver price movements on the oil. Zhang and Wei (2010) examined the relation between gold and oil prices and found a causal relationship between the variables. A nonlinear dynamic relationship between the oil and gold price examined by Lee and Lin (2012) found that the role of gold is determined by the oil price fluctuations. Contrary to the earlier studies, Chang et al. (2013) examined the interrelation between gold, oil and exchange rate and conclude that there is no relation between the selected variable. Baur and McDermott (2010) highlighted that gold is not an effective hedging instrument for the BRIC nations during the stock market turmoil periods. Gurgun and Unalmis (2014) highlighted the hedging properties of gold for the Indian stock market. Concluded that there is a unidirectional spillover from gold returns to the Indian stock returns and there is no volatility spillover from the stock market to the gold. Beckmann et al. 
(2015) found that the gold is paying a safe haven role for the Indian stock markets and the author highlighted the need for non-linear modelling to understand the relationship between gold and the stock market. Chkili (2016) reported the evidence that gold can play a hedge role for the BRIC stock markets and holding the portfolios using gold can reduce the portfolio risk for emerging market portfolios. Ghosh and Kanjilal (2016) reported that the non-linear co-integration between the Indian stock market and the oil. The results also revealed that there is a significant long-run association between the oil and Indian stock market. Bouri, Roubaud, Jammazi, and Assaf (2017) reported a significant bidirectional causality between gold and the Indian and Chinese stock markets. Bouri, Jain, Biswal, and Roubaud (2017) reported a significant relationship between the Indian stock market, gold and oil prices. Miladifar, Mohamadi, and Moghadam (2020) employed a Markov switching Bayesian vector autoregressive model to understand the non-linear relationship between gold, oil and stock markets during upward and downward trends. The results reveal that there is a significant negative association between oil, gold and the stock markets. Lin, Kuang, Jiang, and Su (2019) reported a contagious effect from oil prices, gold prices to stock markets. Tiwari, Adewuyi, and Roubaud (2019) examined the quantile regression on seven economies and reported a positive weak dependency between gold and the stock markets. Wang, Ma, Niu, and He (2020) reported statistically significant association between oil prices on the stock markets. Li, Semeyutin, Lau, and Gozgor (2020) confirm the interconnectedness between the emerging market volatility indices and the oil prices. Enwereuzoh et al. (2021) observed that oil price shocks impact the stock markets of oil-importing nations and oil-exporting nations differently. Reported an interconnectedness between gold and the stock markets. From the prior studies it is evident that there is no conformity in the literature about the relationship between oil, gold and stock markets.

\section{DATA AND METHODOLOGY}

Data: the sample period is selected based on the availability of the data. The Indian implied volatility index is available from $2^{\text {nd }}$ March 2009, hence daily closing prices for the Indian VIX (IVIX), gold implied volatility index (GVIX) and oil implied volatility index (OVIX) are used for the period from $2^{\text {nd }}$ March 2009 to $29^{\text {th }}$ October 2021. GVIX and OVIX data is collected from CBOE and IVIX data is collected from the Indian National Stock Exchange (NSE).

\section{METHODOLOGY}

Asymmetric non-linear ARDL (NARDL) model (Shin et al., 2014) is used to understand the non-linear relationship among the variables GVIX, OVIX and IVIX. The NRDL model is suitable for the stationary variables $\mathrm{I}(0)$, and the variables that are integrating at order one $\mathrm{I}(1)$. The model is not suitable if the variable are stationary at the second order I(2). The asymmetric non-linear ARDL model estimates both long-run and short-run co-integration among the variables in positive and negative directions. The advantage in using NARDL model is the co-integration can be estimated in a single equation framework. The following equation is used to estimate the long-run asymmetric relationship among the variables

$$
Y_{t}=\beta^{+} \sum_{i=1}^{t} \Delta X_{i}^{+}+\beta^{-} \sum_{i=1}^{t} \Delta X_{i}^{-}+\varepsilon_{t}
$$

$Y_{t}$ is a dependent variables $; \beta^{+}$and $\beta^{-}$are the long-run parameters; $\partial_{t}^{+}$and $\partial_{t}^{-}$presents the positive and negative variation in the independent variable.

Generalized form of Asymmetric non-linear ARDL equation is:

$$
\Delta Y_{t}=\alpha+\delta_{y} Y_{t-1}+\delta_{x}^{+} X_{t-1}^{+}+\delta_{x}^{-} X_{t-1}^{-}+\sum_{i=1}^{m} \delta_{i} Y_{t-i}+\sum_{i=0}^{n}\left(\theta_{i}^{+} \Delta X_{t-i}^{+}+\theta_{i}^{-} \Delta X_{t-i}^{-}\right)+\varepsilon_{1 t}
$$

Where, $\delta^{+}$and $\delta^{-}$are the long-run asymmetric coefficients; $\Delta$ represents the changes dependent variable $\mathrm{Y} ; \theta^{+}$and $\theta^{-}$are the short-run asymmetric coefficients. The Long-run asymmetric coefficient 
measures the direction of influence and the speed of adjustment of the independent variables on the dependent variable. The short-run nonlinear asymmetric analysis is used to understand the immediate influence of independent variables on the dependent variable. To test the null hypothesis of the long-run symmetry $\left(\theta^{+}=\theta^{-}\right)$the Wald test is employed. The positive and negative impact of exogenous variables on the dependent variables is measured by the changes in the long-run coefficients. The estimated parameters indicate the non-linear nexus between dependent and independent variables at the long-run equilibrium. Further, Wald test is used to test the short-run symmetry, null hypothesis $\left(\delta^{+}=\right.$ $\left.\delta^{-}\right)$. The positive and negative variations in the dependent variable is estimated by using the parameters. The estimated parameters indicate the positive and negative changes in the exogenous variables at the short-run equilibrium.

\section{EMPIRICAL ESTIMATES AND THE DISCUSSIONS}

Augmented Dickey-Fuller (ADF) and Phillip-Peron (PP) tests are employed to check the order of integration of the variables. All the variables are stationary after the first difference. Table 1 presented the unit root test results.

Table 1. Unit root test results

\begin{tabular}{|l|l|l|l|}
\hline & IVIX & GVIX & OVIX \\
\hline ADF(Level) & -0.8012 & -0.345 & -2.567 \\
\hline PP (Level) & -0.7634 & -0.1865 & -2.875 \\
\hline ADF(First difference) & $22.7654 * * *$ & $28.567 * * *$ & $26.4518 * * *$ \\
\hline PP(First difference) & $27.0834 * * *$ & $28.5891 * * *$ & $36.6541 * * *$ \\
\hline
\end{tabular}

*** is significant at 1 percent level of significance.

The lag composition plays an important role, hence, Akaike Information Criterion (AIC) and Schwartz information criterion (SIC) is used to understand the appropriate lag length.

To understand the co-integration among the selected variables, Nonlinear ARDL bound test is conducted and the results are presented in table 2. The F-statistic value higher than the critical value indicates the existence of non-linear asymmetric long-run co-integration among the variables. The test results indicate the existence of co-integration among the variables. The results are like Zhu et al. (2011), also reported that the stock markets and the oil markets are co-integrated for non-OECD and OECD economies in a panel framework.

Table 2. The NARDL bound test results

\begin{tabular}{|l|l|l|}
\hline Variables & F.Stat & Cointegration \\
\hline IVIX & $4.0121^{* * *}$ & Cointegration \\
\hline GVIX & 2.2981 & No-cointegration \\
\hline OVIX & $7.3821 * * *$ & Cointegration \\
\hline
\end{tabular}

*** is significant at 1 percent level of significance.

The NARDL test results for understanding the long-run asymmetric nexus among OVIX, GVIX and IVIX are reported in table 3. When OVIX and IVIX are considered as dependent variables the Fstatistic value shows a significant asymmetric co-integration among the variables. The equation estimated with OVIX as a dependent variable, results indicates that IVIX does not influence the OVIX in the long-run. Current study results are contradicting to, Zhu et al. (2011), they have reported that the 
stock market influences the oil in the long-run. The study results are coinciding with the findings of Kumar et al. (2019), they also reported that there is no significant co-integration existing between the stock market and oil in long-run. Whereas GVIX tends to have a statistically significant impact on OVIX. An increase (decrease) in GVIX causes (decrease) increase in OVIX, it indicates a statistically significant and negative asymmetric co-integration between GVIX and OVIX in long-run. This shows that the volatility shocks are transmitting from one market to the other. When markets are uncertain investors increase their trading volumes in gold because gold is considered as safe heaven. Increase in trading activity leads to price fluctuations and hence expected volatility. At the same time investors decrease their trading activity in oil markets, it leads to lower future expected volatility. Current study results indicate that the investors prefer to invest in gold compared to oil if gold prices are positively moving.

IVIX as a dependent variable, the estimated equation results are statistically significant and confirm the asymmetric nonlinear association among OVIX, GVIX and IVIX in the long run. The fluctuation in the expected future volatility of the oil market and the gold markets influence the future volatility of the Indian stock market positively. The study results also indicate that the IVIX has no impact on OVIX. This unidirectional relation indicates that the level of dependency of oil-importing nation's stock market volatility on the oil price volatility. Further, results indicate that an increase/decrease in GVIX causes a decrease/increase in IVIX. The results indicate that the Indian stock market's future volatility is sensitive to the expected future volatility of the gold and oil markets. The volatility shocks from these two commodities markets transmit to the Indian stock markets' expected future volatility.

Table 3. NARDL estimated coefficients for the long-run co-integration

\begin{tabular}{|l|r|r|l|l|l|}
\hline \multicolumn{3}{|c|}{ OVIX equation estimated results } & \multicolumn{3}{c|}{ IVIX equation estimated results } \\
\hline Variables & Coefficients & T stat & Variables & Coefficients & T stat \\
\hline IVIX $^{+}$ & 0.7635 & 1.1367 & GVIX $^{+}$ & $0.1763 * * *$ & 4.8128 \\
\hline IVIX $^{-}$ & 0.7865 & 1.1381 & GVIX $^{-}$ & $1.4528 * *$ & 2.5001 \\
\hline GVIX $^{+}$ & $-0.0945 * *$ & 2.3412 & OVIX $^{+}$ & $0.9812 * * *$ & 3.8102 \\
\hline GVIX $^{-}$ & $-0.2387 * * *$ & 3.5128 & OVIX $^{-}$ & $1.4623 * * *$ & 4.1002 \\
\hline C & $2.864 * * *$ & 4.1291 & C & $1.7231 * * *$ & 3.712 \\
\hline
\end{tabular}

*** is significant at 1 percent level of significance. $* *$ indicates the level of significance is $5 \%,{ }^{*}$ indicates the level of significance is $10 \%$

The estimated values for the error correction model are presented in table 4 . The error correction model results for OVIX are negative and statistically significant. The coefficient value is very small (0.0642). These results highlight that the oil volatility will subside after the shock, but the adjustment speed is very slow. The error correction equation estimated for IVIX is also negative and statistically significant. The smaller coefficient values indicate that the speed of adjustment for the IVIX is low and IVIX values will stabilize after the shocks.

The study results show that the fluctuation in GVIX significantly influences the OVIX in the short run. A positive shock to GVIX causes a contemporaneous negative adjustment in OVIX. The OVIX undergoes a negative adjustment for a positive shock to GVIX at lag 1 and 2. The OVIX undergoes a positive adjustment for a positive shock to GVIX at lag 3. A negative shock to GVIX causes a positive adjustment in OVIX.

The error correction model estimated for IVIX suggests that the GVIX and OVIX have a significant influence on IVIX in the short run. The IVIX undergoes a positive adjustment for the shock to IVIX at lag 2, 3 and 4. The IVIX demonstrates a negative contemporaneous adjustment to the positive 
shock to GVIX at lag 1 and 2. A negative shock to GVIX causes a negative contemporaneous price adjustment in IVIX in the short-run. IVIX exhibits a positive adjustment to the positive stock to OVIX. The IVIX demonstrates a positive adjustment to the negative and positive shocks to the OVIX.

Table 4. Error correction for NARDL model estimated results

\begin{tabular}{|c|c|c|c|c|c|}
\hline \multicolumn{3}{|c|}{$\begin{array}{l}\text { Error correction results for NARDL model } \\
\text { (OVIX) }\end{array}$} & \multicolumn{3}{|c|}{$\begin{array}{l}\text { Error correction results for NARDL model } \\
\text { (IVIX) }\end{array}$} \\
\hline Variables & Coefficients & T stat & Variables & Coefficients & T stat \\
\hline OVIX $_{\mathrm{t}-1}$ & $-0.1873 * * *$ & -3.8710 & IVIX $_{\mathrm{t}-1}$ & 0.8723 & 1.9842 \\
\hline OVIX $_{\mathrm{t}-\mathrm{s}}$ & $-0.0129 * *$ & -4.0086 & IVIX $_{t-2}$ & $0.3481 * *$ & 2.0981 \\
\hline GVIX $^{+}$ & -0.0321 & -0.6823 & IVIX $_{\mathrm{t}-3}$ & $1.7823 * * *$ & 4.6528 \\
\hline $\operatorname{GVIX}^{+}{ }_{\mathrm{t}-1}$ & $-0.1287 * *$ & -2.001 & IVIX $_{\mathrm{t}-4}$ & $0.9821 * * *$ & 3.9812 \\
\hline $\mathrm{GVIX}^{+}{ }_{\mathrm{t}-2}$ & $-1.9187 * * *$ & -4.981 & $\mathrm{GVIX}^{+}$ & -1.7635 & -1.9823 \\
\hline GVIX $^{+}{ }_{t-3}$ & $0.9534 * * *$ & 2.4123 & GVIX $^{+}{ }_{t-1}$ & $-0.9126 * *$ & -2.1348 \\
\hline GVIX $^{-}$ & $0.5328 * *$ & 0.0961 & GVIX $^{+}{ }_{t-2}$ & $-1.9812 * * *$ & -3.1287 \\
\hline $\mathrm{GVIX}^{-}{ }_{\mathrm{t}-1}$ & 3.2341 & 0.9128 & GVIX $^{-}$ & -0.6381 & -1.6522 \\
\hline $\mathrm{GVIX}_{\mathrm{t}-2}^{-}$ & 2.0981 & -6.7218 & GVIX $^{-} \mathrm{t}-1$ & $-.07623 * *$ & -2.9912 \\
\hline \multirow[t]{4}{*}{ ECM (-1) } & $-0.0642 * * *$ & & OVIX $^{+}$ & $2.001 * * *$ & 3.9741 \\
\hline & & & $\mathrm{OVIX}^{+}{ }_{\mathrm{t}-1}$ & $3.1260 * * *$ & 4.6914 \\
\hline & & & OVIX $^{-}$ & $0.3971 * * *$ & 3.001 \\
\hline & & & $\operatorname{ECM}(-1)$ & $-0.0489 * * *$ & -9.3912 \\
\hline
\end{tabular}

*** is significant at 1 percent level of significance. $* *$ indicates the level of significance is $5 \%$,* indicates the level of significance is $10 \%$

The Wald test estimated results for short-term and long-term symmetric is presented in the table5. The Wald test estimated results are presented in table 5. The long-run (WLR) and short-run (WSR) result indicates that the OVIX has a long-run symmetric relationship with IVIX and the shortrun symmetric relationship with GVIX. The IVIX exhibits a short-term symmetric relationship with GVIX and OVIX.

Table 5. Wald test results for symmetric long-term and short-term cointegration

\begin{tabular}{|l|l|r|l|r|r|}
\hline \multicolumn{3}{|c|}{ Wald Test Results for OVIX } & \multicolumn{3}{c|}{ Wald Test Results for IVIX } \\
\hline variable & WLR & \multicolumn{1}{|c|}{ WSR } & Variables & WLR & \multicolumn{1}{c|}{ WSR } \\
\hline GVIX & 7.6162 & $2.716^{* *}$ & GVIX & 11.6352 & $2.7634^{* *}$ \\
\hline IVIX & $11.8372^{* * *}$ & 7.3291 & OVIX & 11.84 & $7.323^{* *}$ \\
\hline
\end{tabular}

*** is significant at 1 percent level of significance. ** indicates the level of significance is $5 \%$, indicates the level of significance is $10 \%$

\section{CONCLUSIONS AND IMPLICATIONS}

The present study conducted on GVIX, OVIX and IVIX for the period from $2^{\text {nd }}$ March 2009 to $29^{\text {th }}$ October 2021 revealed the asymmetric long-run and short-run association among the selected variables. 
The uniqueness of this study lies with the usage of implied volatility indices to test the asymmetric nonlinear association among gold, oil and the Indian stock markets. In the sense, current study results indicate the forward-looking uncertainty due to the uncertainty among the other selected variables.

The empirical evidence from the study indicate short-run, long-run association among implied volatility of gold, oil and the Indian stock market. The results are similar to the findings of Jain and Biswal (2016). The current study reports the existence of asymmetric association among the selected variables when implied volatility index of oil and the Indian stock markets are considered as dependent variables. The NARDL co-integration test for the long-run indicates a statistically significant and negative asymmetric co-integration between GVIX and OVIX in long-run. This indicates that the investors are moving their trading activity from oil markets to gold during the uncertain market conditions.

The current study results confirm that there is a contemporaneous asymmetric nonlinear association among OVIX, GVIX and IVIX in long-run. The fluctuation in the expected future volatility of the oil market and the gold markets influence the future volatility of the Indian stock market positively. The results indicate that the Indian stock market's future volatility is sensitive to the expected future volatility of the gold and oil markets. India being the importer of these two commodities, the volatility shocks from these two commodities markets transmit to the Indian stock markets' expected future volatility. So Investors may make use of the results to enter into appropriate derivative contacts to hedge their portfolio.

The symmetric test for long term and short term association indicates that OVIX has the longrun symmetric relationship with IVIX and the short-run symmetric relationship with GVIX. The IVIX exhibits short-term symmetric relationship with GVIX and OVIX. It shows that the implied volatility of Indian stock market is influencing the expected volatility of oil and gold in the short-run symmetrically. The stock market performance as the barometer for the Indian economic activity, higher the economic activity higher the demand for oil. The higher demand from the biggest consumer may influence the oil prices positively in short-run. The results are important to the managers to enter into derivative contracts to hedge against the increasing production cost due to increasing oil prices.

Further study should focus to understand, whether the relationship among implied volatility indices of oil, gold and the Indian stock market changes with the regime-switching behaviour of these indices or not.

\section{AUTHOR CONTRIBUTIONS}

Conceptualization: Jyothi Chittineni

Data Curation: Jyothi Chittineni

Formal Analysis: Jyothi Chittineni

Funding Acquisition: Jyothi Chittineni

Investigation: Jyothi Chittineni

Methodology: Jyothi Chittineni

Project Administration: Jyothi Chittineni

Resources: Jyothi Chittineni

Software: Jyothi Chittineni

Supervision: Jyothi Chittineni

Validation: Jyothi Chittineni

Visualization: Jyothi Chittineni

Writing - Original Draft: Jyothi Chittineni

Writing - Review \& Editing: Jyothi Chittineni

\section{CONFLICT OF INTEREST STATEMENT}

The author declare that he has no competing interests. 


\section{ACKNOWLEDGEMENT}

I would like to thank Mr. Narasimha Rao Kurra for his review suggestions and his support in conducting this study.

\section{REFERENCES}

Baur, D. G., \& McDermott, T. K. (2010). Is gold a safe haven? International evidence. Journal of Banking \& Finance, 34(8), 1886-1898.

Beckmann, J., Berger, T., \& Czudaj, R. (2015). Does gold act as a hedge or a safe haven for stocks? A smooth transition approach. Economic Modelling, 48, 16-24.

Bouri, E., Roubaud, D., Jammazi, R., \& Assaf, A. (2017). Uncovering frequency domain causality between gold and the stock markets of China and India: Evidence from implied volatility indices. Finance Research Letters, 23, 23-30.

Chang, H. F., Huang, L. C., \& Chin, M. C. (2013). Interactive relationships between crude oil prices, gold prices, and the NT-US dollar exchange rate-A Taiwan study. Energy policy, 63, 441-448.

Chkili, W. (2016). Dynamic correlations and hedging effectiveness between gold and stock markets: Evidence for BRICS countries. Research in International Business and Finance, 38, 22-34.

Enwereuzoh, P. A., Odei-Mensah, J., \& Junior, P. O. (2021). Crude oil shocks and African stock markets. Research in International Business and Finance, 55, 101346.

Ghosh, S., \& Kanjilal, K. (2016). Co-movement of international crude oil price and The Indian stock market: Evidences from nonlinear cointegration tests. Energy Economics, 53, 111-117.

Gürgün, G., \& Ünalmış, İ. (2014). Is gold a safe haven against equity market investment in emerging and developing countries?. Finance Research Letters, 11(4), 341-348.

Hammoudeh, S., \& Choi, K. (2007). Characteristics of permanent and transitory returns in oil-sensitive emerging stock markets: The case of GCC countries. Journal of International Financial Markets, Institutions and Money, 17(3), 231-245.

Jain, A., \& Biswal, P. C. (2016). Dynamic linkages among oil price, gold price, exchange rate, and stock market in India. Resources Policy, 49, 179-185.

Kumar, S., Pradhan, A. K., Tiwari, A. K., \& Kang, S. H. (2019). Correlations and volatility spill overs between oil, natural gas, and stock prices in India. Resources Policy, 62, 282-291

Lee, W. C., \& Lin, H. N. (2012). Threshold effects in the relationships between USD and gold futures by panel smooth transition approach. Applied Economics Letters, 19(11), 1065-1070.

Li, H., Semeyutin, A., Lau, C. K. M., \& Gozgor, G. (2020). The relationship between oil and financial markets in emerging economies: The significant role of Kazakhstan as the oil exporting country. Finance Research Letters, 32, 101171.

Lin, L., Kuang, Y., Jiang, Y., \& Su, X. (2019). Assessing risk contagion among the Brent crude oil market, London gold market and stock markets: Evidence based on a new wavelet decomposition approach. The North American Journal of Economics and Finance, 50, 101035. 
Miladifar, M., Mohamadi, T., \& Moghadam, B. A. (2020). Investigating the Effect of Oil Price Shocks on Stock and Gold Prices During Periods of Decline and Increase in Oil Prices. Quarterly Energy Economics Review, 15(63), 209-241.

Raj, J., Dhal, S., \& Jain, R. (2008). Imported inflation: The evidence from India. Reserve Bank of India Papers, 29(3), 69-117.

Reboredo, J. C. (2013). Is gold a safe haven or a hedge for the US dollar? Implications for risk management. Journal of Banking \& Finance, 37(8), 2665-2676.

Sari, R., Hammoudeh, S., \& Soytas, U. (2010). Dynamics of oil price, precious metal prices, and exchange rate. Energy Economics, 32(2), 351-362.

Shin, Y., Yu, B., \& Greenwood-Nimmo, M. (2014). Modelling asymmetric cointegration and dynamic multipliers in a nonlinear ARDL framework. In Festschrift in honor of Peter Schmidt (pp. 281314). Springer, New York, NY.

Soytas, U., Sari, R., Hammoudeh, S., \& Hacihasanoglu, E. (2009). World oil prices, precious metal prices and macroeconomy in Turkey. Energy Policy, 37(12), 5557-5566.

Tiwari, A. K., Adewuyi, A. O., \& Roubaud, D. (2019). Dependence between the global gold market and emerging stock markets $(E 7+1)$ : Evidence from Granger causality using quantile and quantileon-quantile regression methods. The World Economy, 42(7), 2172-2214.

Wang, L., Ma, F., Niu, T., \& He, C. (2020). Crude oil and BRICS stock markets under extreme shocks: New evidence. Economic Modelling, 86, 54-68.

Zhang, Y. J., \& Wei, Y. M. (2010). The crude oil market and the gold market: Evidence for cointegration, causality and price discovery. Resources Policy, 35(3), 168-177.

Zhu, H. M., Li, S. F., \& Yu, K. (2011). Crude oil shocks and stock markets: A panel threshold cointegration approach. Energy Economics, 33(5), 987-994.

\section{Copyrights}

Copyright for this article is retained by the author(s), with first publication rights granted to the journal. This is an open-access article distributed under the terms and conditions of the Creative Commons Attribution license (https://creativecommons.org/licenses/by/4.0) 